\title{
Thousand Per Liter
}

National Cancer Institute

\section{Source}

National Cancer Institute. Thousand Per Liter. NCI Thesaurus. Code C105519.

A concentration unit expressed as a number or quantity of objects in thousands per unit of volume equal to one liter. 